\title{
North Central Indiana AHEC: STEPS Program Impact
}

Katie Ceglio ${ }^{1}$, Julianne Stout ${ }^{2}$

${ }^{1}$ Indiana University School of Medicine; ${ }^{2}$ Indiana University School of Medicine-West Lafayette,

Departments of Internal Medicine and Pediatrics

\section{Background/Objective:}

North Central Indiana Area Health Education Center (NCI AHEC) aims to encourage rural students in their service district to pursue healthcare. In light of rural healthcare shortages found in Indiana, they implemented the Successfully Training and Educating Pre-medical Students (STEPS) program, available to college juniors at Indiana University - Kokomo. Through MCAT prep courses, workshops about interviews, and job shadowing, the goal of the program is for more rural students to be accepted into local medical schools, to then return to practice in that rural area. This case study examines the initial impacts of the STEPS program and the path to healthcare for a student at IU - Kokomo.

\section{Methods:}

A mixed methods study was conducted. First, a survey was administered by $\mathrm{NCl}$ AHEC to students who participated in the STEPS program using a retrospective pre/post design. The quantitative data, representing students' opinions and goals, was aggregated and interpreted. An interview was then done with a previous STEPS student. This student's experience was analyzed.

\section{Results:}

Participation in the STEPS program resulted in increased knowledge about healthcare careers and plans to pursue further education for healthcare careers across all students. The STEPS program has identified strengths, including activities that increase student commitment to pursuing healthcare and mentorship for students. Areas for growth were also identified, including adding application assistance, decreasing competition for resources, and increasing efforts to keep students in Indiana.

\section{Conclusion and Potential Impact:}

Initial evaluation suggests that the STEPS program is beneficial in assisting rural students on their path to a career in healthcare. Analysis of the interviewee's experience provides recommendations for improvements of the STEPS program in the future. 